\title{
Chemo-enzymatic Labeling for Rapid Assignment of RNA Molecules
}

Andrew P. Longhini, Regan M. LeBlanc, T. Kwaku Dayie*

\author{
T. Kwaku Dayie* \\ Department of Chemistry \& Biochemistry \\ University of Maryland \\ Biomolecular Sciences Building (296) \\ 8314 Paint Branch Dr. \\ College Park, Maryland 20782 (USA) \\ Email: dayie@umd.edu \\ Fax: (+1)-301-314-0386
}

\begin{abstract}
Even though Nuclear Magnetic Resonance (NMR) spectroscopy is one of the few techniques capable of determining atomic resolution structures of RNA, it is constrained by two major problems of chemical shift overlap of resonances and rapid signal loss due to line broadening. Emerging tools to tackle these problems include synthesis of atom specifically labeled or chemically modified nucleotides. Herein we review the synthesis of these nucleotides, the design and production of appropriate RNA samples, and the application and analysis of the NMR experiments that take advantage of these labels.
\end{abstract}


1. Introduction

Ribonucleic acids are involved in a broad array of functions [1]. Yet, understanding how RNA structure and dynamics form an integral part of their functions is still lacking. As of December 2015, about 106,496 protein structures had been deposited in the RCSB protein data bank (www.rcsb.org), while at the same time, only 1166 RNA and 1601 DNA structures had been deposited [2]. Addressing this discrepancy is therefore important to further our understanding of the variety of roles RNA molecules play. Nuclear magnetic resonance (NMR) spectroscopy has made fundamental contributions to this end [3-8]. In particular, recent developments in the synthesis of site-specifically labeled ribonucleotides [3, 4, 8-10], when paired with recent advancements in various NMR spectroscopic techniques [11-17], promise to position NMR as an even more effective tool for determining high-resolution structures of RNAs. These newer methodologies will complement earlier NMR developments [18-24] as well as various site-specific selective and segmental labeling for RNAs [25-30] and DNAs [31-43]. In this review, we focus on site- and atom-specific isotopic enrichment for RNA synthesis.

The first hurdle that must be addressed in any high-resolution RNA structural analysis by NMR is the specific assignment of individual resonances to their corresponding atomic positions. In protein NMR, this is achieved by a sequential, though-bond walk of the backbone [44]. However in RNA, the low chemical shift dispersion of the phosphorus backbone has made an analogous walk extremely difficult [45-50]. To get around this problem a through-space NOESY walk has traditionally been applied [24, 51-60]. Using heteronuclear edited and filtered NOESY experiments atoms $<5 \AA$ apart are not only correlated but also are selected if they are attached to a labeled ${ }^{13} \mathrm{C}$ carbon nuclei, or rejected otherwise $[57,61]$. Here 'filter' denotes isotopic labeled signal rejection whereas 
'edit' denotes selection of such signals. Thus a ${ }^{13} \mathrm{C}$-filter removes the signals of ${ }^{13} \mathrm{C}$ isotopic-attached protons, but a ${ }^{13} \mathrm{C}$-edit selects the isotope-attached proton magnetization [61]. For RNA, this criteria is satisfied in the distances between the $\mathrm{C}^{\prime} / \mathrm{C2}{ }^{\prime}$ and $\mathrm{C} 2 / \mathrm{C} 6 / \mathrm{C} 8$ attached protons in A-form helices.

The development of isotopic labeling strategies in the 1990s [62-69] led to the design of 2D and 3D experiments [22, 23, 70]. With labeling, edited and filtered experiments became possible such that by selecting out only the protons attached to ${ }^{13} \mathrm{C}$ labeled heteroatoms the spectra recorded become less crowded [57]. This greatly simplifies the assignment process. Furthermore, introduction of deuterium into labeled nucleotides reduces spectral crowding even more and makes possible the assignment of even larger RNAs [51, 56, 68$69,71-77]$. We have recently published a new development in the assignment procedure that takes advantage of the ability to site-specifically label nucleotides with various labeling patterns. We have discussed previously how the production of these nucleotides is best achieved by using a combination of chemical and enzymatic synthesis [9]. This review focuses on the use of this coupled approach to first produce site- and atom-specific labeled nucleotides, and then plan and produce appropriately labeled RNAs. Finally we review the application of NOESY pulse sequences and the analysis of the resulting NMR spectra (Figure 1). 


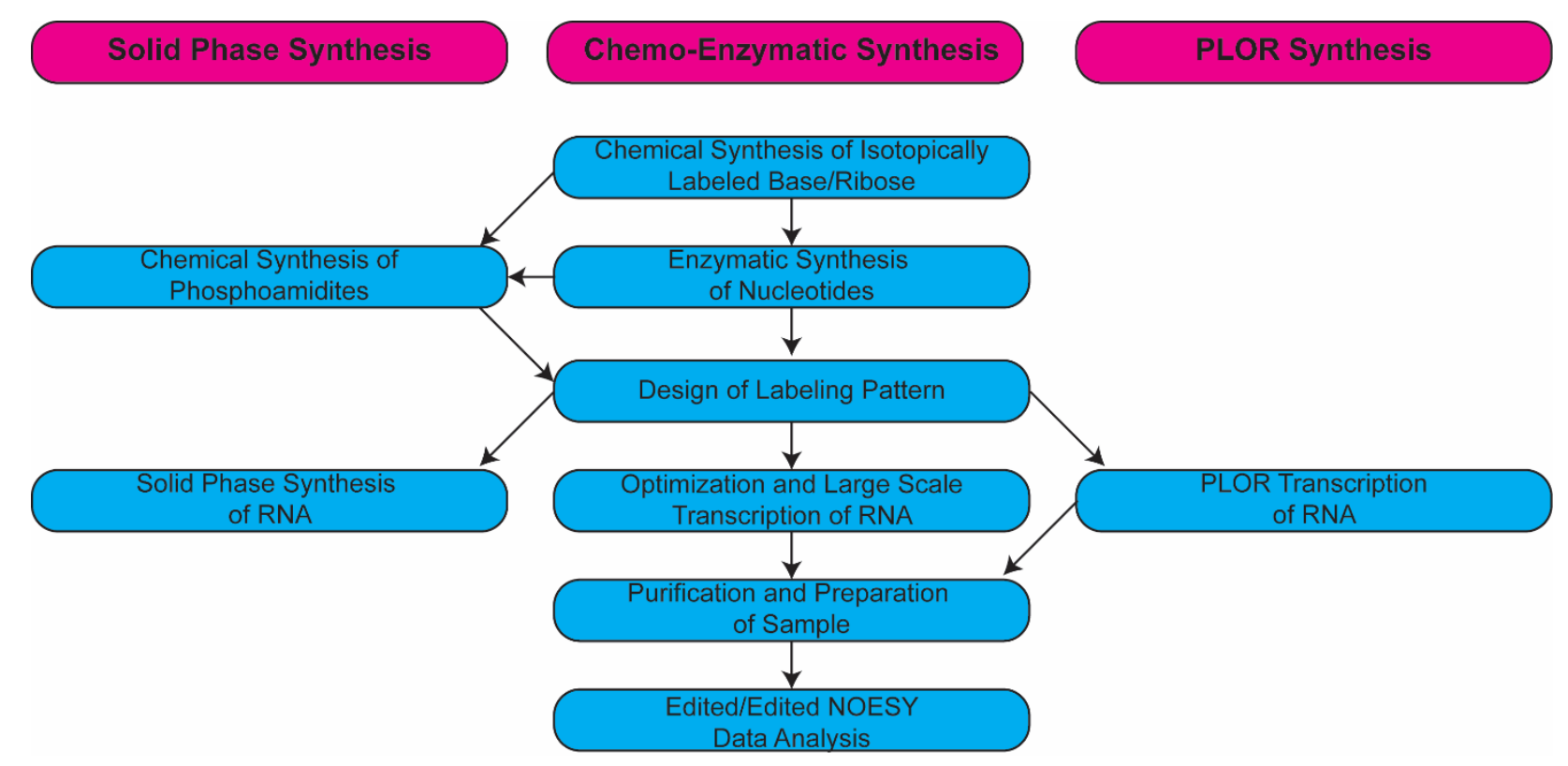

2. Chemoenzymatic Synthesis of Nucleotides

Recently we have published methods for the chemo-enzymatic synthesis of pyrimidine and purine nucleotides $[3,4,9]$. Compared to previously published techniques, our method offers a substantial improvement [72-73,78-83]. In brief, our synthesis is shorter, more general, and produces higher yields. Whereas previous methods produced all four nucleotides as a mixture that needed separation into individual nucleotides, our method synthesizes one nucleotide at a time. This bypasses the tedious chromatographic procedures required for isolating nucleotides from a mixture of all four bases. This is important for our downstream applications. Advances have been made in NMR selective pulse technologies that appear to obviate the need for site- and atom-specific labeled nucleotides [84-94]. Nonetheless, we showed recently that an alternative, straightforward and effective solution for overcoming the problem of spectral crowding and $\mathrm{J}$-coupling complements these existing methodologies [3, 9]. Here, we revisit these recently described techniques wherein the judicious selection of these specific isotopic 
patterns enables the production of highly customized samples that circumvent many of the previous problems of spectral crowding [3].

\subsection{Pyrimidines}

A detailed protocol for the synthesis of pyrimidine nucleotides has been previously published [4]. In an attempt to make the process as streamlined as possible, we developed His-tagged versions of proteins that are prohibitively expensive or commercially unavailable [95]. With these proteins in hand, 50 mg of nucleotides are readily produced per batch using the following conditions: for a $10 \mathrm{ml}$ reaction buffer (50 $\mathrm{mM} \mathrm{Na}_{3} \mathrm{PO}_{4} \mathrm{pH} 7.5$ buffer with $10 \mathrm{mM} \mathrm{MgCl}$, 2 mM Ampicillin, $10 \mathrm{mM}$ DTT, and 0.1 $\mathrm{mg} / \mathrm{mL}$ BSA) supplemented with a dATP regeneration system (0.5 mM dATP, $100 \mathrm{mM}$ Creatine Phosphate, $0.005 \mathrm{mg} / \mathrm{mL}$ Creatine Kinase, $0.010 \mathrm{U} / \mu \mathrm{L}$ Myokinase, and 0.004 $\mathrm{U} / \mu \mathrm{L}$ TIPP), the reaction is initiated with addition of $8 \mathrm{mM}$ specifically labeled uracil, 8 $\mathrm{mM}$ specifically labeled ribose, $0.005 \mathrm{U} / \mu \mathrm{L}$ ribokinase, $0.0003 \mathrm{U} / \mu \mathrm{L}$ PRPPS, and 0.005 $\mathrm{U} / \mu \mathrm{L}$ UPRT. The reaction is incubated at $37^{\circ} \mathrm{C}$ for $5-8$ hours at which point $10 \mathrm{mM} \mathrm{KCl}$, $0.1 \mathrm{mM}$ dATP, $10 \mathrm{mM}$ Creatine Phosphate, and $0.05 \mathrm{mg} / \mathrm{mL}$ NMPK are added to phosphorylate the NMP to NTP. After incubation at $37^{\circ} \mathrm{C}$ overnight, reactions are purified over a boronate affinity column.

Purified UTP is converted into CTP in a simple procedure and at similar scales. $2 \mathrm{mM}$ UTP is added to a reaction buffer ( $2 \mathrm{mM} \mathrm{MgCl}_{2}, 0.5 \mathrm{mM} \mathrm{dATP}, 100 \mathrm{mM}$ Creatine Phosphate, $0.005 \mathrm{mg} / \mathrm{mL}$ Creatine Kinase, $0.010 \mathrm{U} / \mu \mathrm{L}$ Myokinase, $0.10 \mathrm{mg} / \mathrm{mL}$ CTPS, and $20 \mathrm{mM}$ ammonium chloride) and the $\mathrm{pH}$ is adjusted to 8.0 with $\mathrm{NaOH}$. Reactions are again purified with boronate affinity chromatography. The price of the amount of nucleotides produced are comparable to or even cheaper than commercially available uniformly labeled nucleotides. 


\subsection{Purines}

Adenine and guanine are produced in a manner similar to the one described above. For both reactions, this reaction buffer $\left(50 \mathrm{mM} \mathrm{Na}_{3} \mathrm{PO}_{4} \mathrm{pH} 7.5\right.$ buffer with $10 \mathrm{mM} \mathrm{MgCl}_{2}, 2$ $\mathrm{mM}$ Ampicillin, $10 \mathrm{mM} \mathrm{DTT}$, and $0.1 \mathrm{mg} / \mathrm{mL}$ BSA) is supplemented with a dATP regeneration system $(0.5 \mathrm{mM}$ dATP, $100 \mathrm{mM}$ Creatine Phosphate, $0.005 \mathrm{mg} / \mathrm{mL}$ Creatine Kinase, $0.010 \mathrm{U} / \mu \mathrm{L}$ Myokinase, and $0.004 \mathrm{U} / \mu \mathrm{L}$ TIPP). For GTP, $5 \mathrm{mM}$ specifically labeled guanine is added to this mixture, together with $6 \mathrm{mM}$ labeled ribose, $0.005 \mathrm{U} / \mu \mathrm{L}$ ribokinase, $0.0003 \mathrm{U} / \mu \mathrm{L}$ PRPPS, and $0.005 \mathrm{U} / \mu \mathrm{L}$ XGPRT. After incubating at $37^{\circ} \mathrm{C}$ for 5 hours, guanylate kinase is added and the reaction is left to proceed overnight. For ATP, $10 \mathrm{mM}$ labeled adenine, $10 \mathrm{mM}$ labeled ribose, $0.005 \mathrm{U} / \mu \mathrm{L}$ ribokinase, $0.0003 \mathrm{U} / \mu \mathrm{L}$ PRPPS, and $0.005 \mathrm{U} / \mu \mathrm{L}$ APRT are added. The reaction is complete after 6 hours at $37^{\circ} \mathrm{C}$. Again reactions are purified over a boronate affinity column $[3,63]$.

3. Design of a Selective Incorporation Scheme

\subsection{Overcoming Crowding}

A major hindrance to NMR studies of RNA is the low dispersion of chemical shifts due to the low chemical diversity of nucleotides. A typical NOESY experiment for a 27-nt RNA fragment encompassing the highly conserved aminoacyltRNA anticodon site (A-site) of 16S rRNA on the 30 S subunit illustrates this point (Figure 2). In black is the NOESY spectrum of a uniformly ${ }^{13} \mathrm{C} /{ }^{15} \mathrm{~N}$ labeled sample, and in blue an edited/edited NOESY (where only protons attached to ${ }^{13} \mathrm{C}$ are selected) with our alternating labeling scheme. By using edited/edited experiments (discussed in detail below) on our alternating sample the spectral complexity is greatly reduced. Further, as the number of nucleotides increases, so does the complexity of the spectra. In the past this complexity problem has been addressed by using samples with 
one nucleotide uniformly ${ }^{13} \mathrm{C},{ }^{15} \mathrm{~N}$-labeled, with the other nucleotides either unlabeled or deuterated [30]. While this technique has proven to be instrumental in the assignment of a number of large (>45 nt) RNAs, it requires the use of a large number of samples (at least 10). As these RNA samples have both uniformly ${ }^{13} \mathrm{C}$-labeled and deuterated nucleotides, the cost becomes prohibitively expensive. This effectively restricts the study of large RNAs to a very few well equipped and funded labs. Our methodology is general enough to produce these labels and others not currently commercially available, and all at substantially ( 2-5fold) reduced prices. Furthermore, the previous deuteration strategy combined with fullylabeled nucleotides leads to many gaps in the NOESY "ladder". This is undesirable and can lead to ambiguity in the assignment.

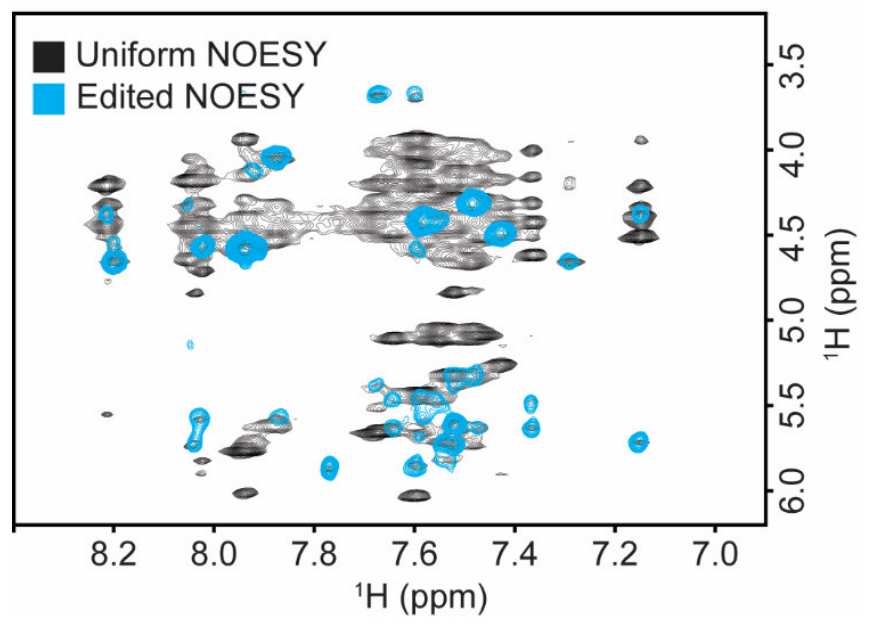

\subsection{General Strategy for Labeling Multiple Samples}

Our strategy relies on making 2 samples for the complete NOESY assignment of the C1'/H1', C2'/H2', C6/H6, C8/H8 resonances in A-form RNA helical regions (Figure 3). As we have previously discussed, both the H1' and H2' protons of a nucleotide are within 5 $\AA$ of the base $\mathrm{H} 6 / \mathrm{H} 8$ protons of the same nucleotide and also of the $\mathrm{H} 6 / \mathrm{H} 8$ protons of the previous nucleotide $\left(5^{\prime}\right)$ in the sequence $[3,96]$. Correlating the sugar protons of a nucleotide with its own base protons, followed by the correlation of those same sugar 
protons with those of the adjacent base protons is the general approach for the assignment of helical regions. However, if the C1' of every nucleotide in the helix is labeled, then this region of the spectrum quickly becomes too crowded to yield unambiguous correlations and the connectivity is lost. One solution is to remove the C1' labeling from a subset of the nucleotides. Under these conditions however, the connectivity is again lost. Instead, by replacing the removed C1' labeled nucleotides with C2' labeled sugars, the walk is persevered and the problem of crowding is also addressed (Figure 4) [96]. Overlap of strong correlations between intra-nucleotide H5 and $\mathrm{H} 6$ within the same region of the spectra further complicates the analysis.

Deuteration of the C5 position removes these strong intra-nucleotide NOEs further simplifying the NOESY walk [3, 9, 68, 71, 74].<smiles>[2H]c1c[nH]c(=O)[nH]c1=O</smiles><smiles>[2H]c1c[nH]c(=O)nc1N</smiles><smiles>Nc1ncnc2[nH]cnc12</smiles><smiles>Nc1nc2[nH]cnc2c(=O)[nH]1</smiles><smiles>OC[C@H]1O[C@H](O)[C@@H](O)[C@@H](O)[C@H]1O</smiles><smiles>OC[C@H]1O[C@H](O)[C@@H](O)[C@H](O)[C@H]1O</smiles>
UTP, CTP, ATP, GTP 


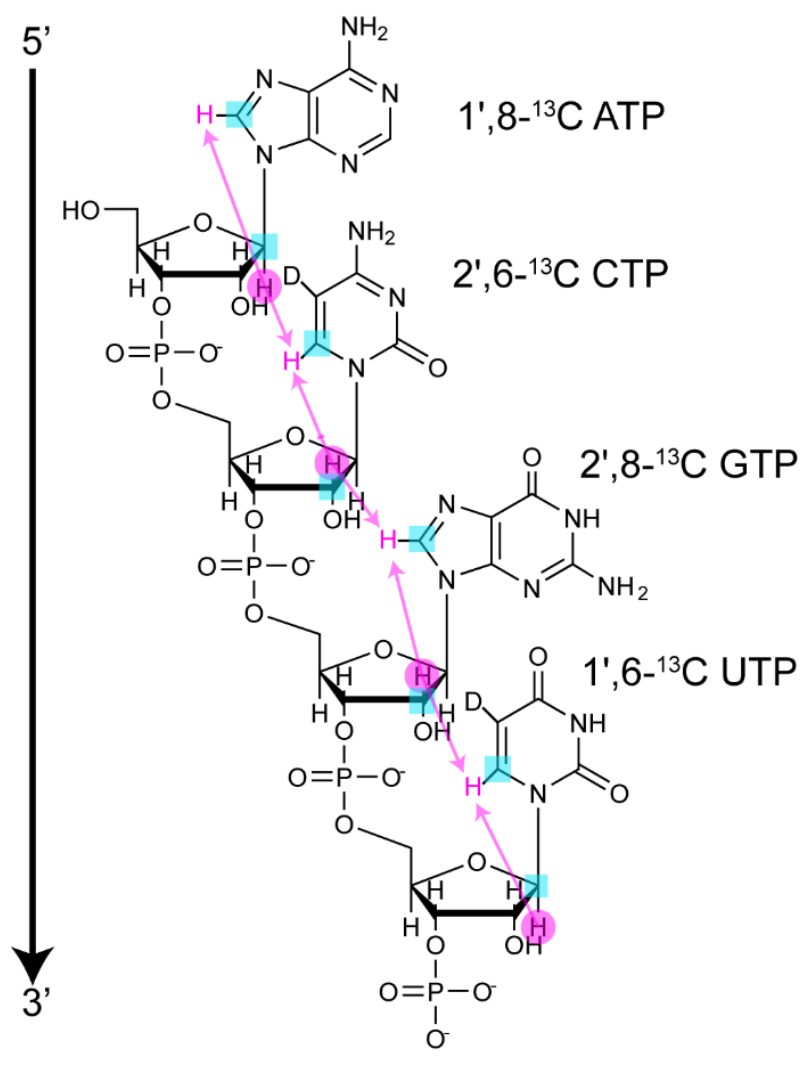

Using our chemo-enzymatic approach it is relatively easy to achieve this 1 ' or 2 ' ${ }^{13} \mathrm{C}$ ribose labeling in the context of $\mathrm{C} 6$ or $\mathrm{C} 8$ labeled base. This creates 8 different combinations of nucleotides which can be mixed and matched to produce any desired pattern of labeling conducive for assignments (Figure 3). Various ribose patterns are commercially available but bases have a more limited repertoire of commercially available labels. Our chemo-enzymatic approach has enabled us to expand the available atom specific base labels $[3,4,9,97]$. This is especially helpful for uracil, on which the $\mathrm{H} 5$ position is replaced by deuterium to improve the relaxation properties at the $\mathrm{H} 6$ position and remove crowding in the NOESY spectrum. With these nucleotides in hand, typical in vitro synthesis protocols can be followed to produce labeled RNAs [4, 9, 97]. 
4. Preparation and NOESY Experiments on an Alternating Labeled Sample

4.1. Design of an Alternating Labeled Sample

Ideally, alternating labeled samples are designed based on the availability of a priori knowledge of the distribution of the $\mathrm{C}^{\prime} / \mathrm{C} 2$ ' resonances for each of the 4 nucleotides. In this way any overlap can be strategically avoided. Initially, it is therefore best to start with a uniformly ${ }^{13} \mathrm{C} /{ }^{15} \mathrm{~N}$ labeled sample to ascertain whether alternately placed $\mathrm{C} 1$ '/C2' pyrimidine or purine resonances would or would not cluster together.

Once the appropriate labeling pattern is decided on, transcription optimization is carried out using a sparse array in which [ $\left.\mathrm{MgCl}_{2}\right]$, [NTPs], and [T7] are varied [98, 99]. Recent work has suggested addition of DMSO to the transcription reaction can produce RNAs with reduced chemically heterogeneous 5' and 3' ends, and including this as an additional variable may help to improve transcription yields [99]. RNA is first transcribed on a small scale of $\sim 20 \mu \mathrm{L}$ per reaction. The three best conditions from this first round are used for a medium scale up of $\sim 500 \mu \mathrm{l}$, and the best conditions from this last round are used for a scale up to the full size transcription (usually $10-20 \mathrm{ml}$ of reaction). Samples are purified by denaturing PAGE electrophoresis followed by electroelution or anion exchange chromatography [100-102]. Pooled fractions are buffer exchanged extensively ( 12-24 h each) against $0.5 \mathrm{M}$ potassium chloride, $10 \mathrm{mM}$ EDTA, and then $0.1 \mathrm{mM}$ EDTA, and finally against two changes of ddH2O water [98]. The RNA is buffer exchanged with an ultraspin filter with a molecular weight cut-off (MWCO) of 3kDa (the MWCO is chosen to be at least 2.5 times smaller than the MW of the RNA of interest) to remove salts before being finally concentrated to the desired volume. After dialysis, the RNA is resuspended into the appropriate buffer required for NMR with or without requisite cations, trace of sodium azide, and DSS for referencing $[98,99]$.

4.2. Use of Edited, Filtered and Selected Experiments to take Full Advantage of New Labels 
Given the tedious nature of resonance assignment, it is important to combine new isotopic labeling strategies with NOESY experiments that use filtering, editing and separation techniques [61]. Again by filtering, we mean rejection of magnetization of protons that are scalar coupled to ${ }^{13} \mathrm{C}$, by editing we mean selection of magnetization of protons that are scalar coupled to ${ }^{13} \mathrm{C}$, and by ${ }^{13} \mathrm{C}$ separation we mean allowing ${ }^{13} \mathrm{C}$ chemical shift to evolve to produce an additional spectral dimension [61]. The unique labeling scheme presented here was implemented to preserve limited through-space transfers within NOESY experiments with filtering and editing double purge modules. Thus, by performing an edited/edited NOESY, the only NOESY crosspeaks that appear in a spectrum are from those nuclei that are directly attached to ${ }^{13} \mathrm{C}$ labeled carbons. This significantly reduces the crowding in the NOESY spectrum, and also helps to identify the resonances from nucleotides labeled on their C2' and C1' resonances since they resonate in discrete regions of the spectrum. Figure 5 demonstrates a NOESY walk for the 27-nt bacterial A-Site RNA labeled with 1 ', $8-{ }^{13} \mathrm{C}$ ATP, 1 ',6${ }^{13} \mathrm{C}-5-{ }^{2} \mathrm{H}$ UTP, 2 , $8{ }^{13} \mathrm{C}$ GTP, and 2 ', $6-{ }^{13} \mathrm{C}-5-{ }^{2} \mathrm{H}$ CTP.

A

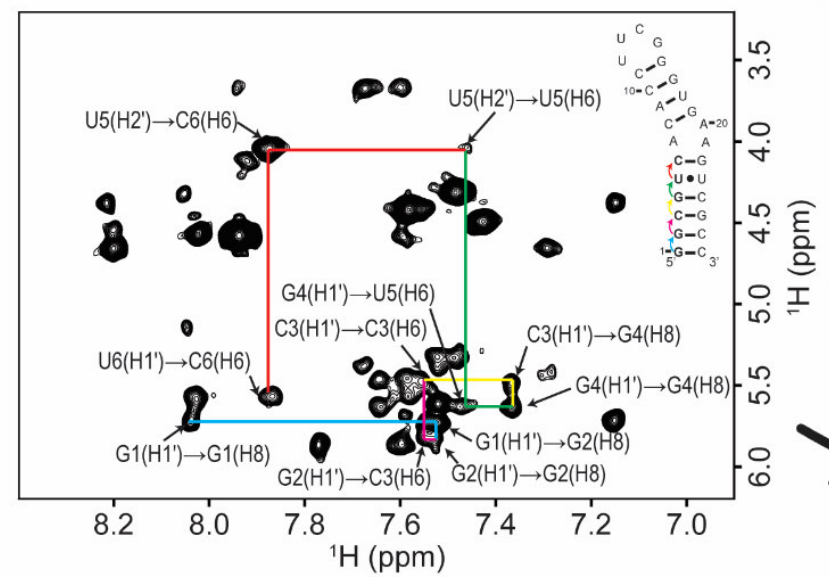

B

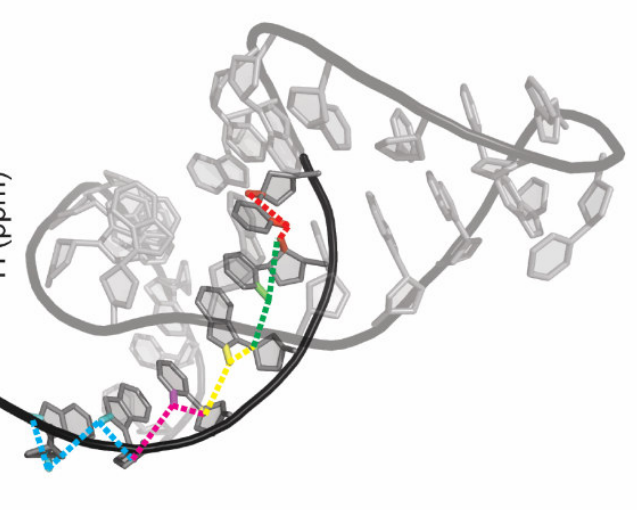

4.3. Discussion of Cases that Might be Encountered 
As the size of the RNAs under investigation increases, more specialized labeling patterns may be required. One can envision scenarios in which the base region of the spectrum becomes extremely crowded. In this case, information will again be lost. One possible solution would to be the synthesis of key nucleotides with unlabeled bases, while keeping the sugars labeled. In this way minimal NOESY connectivity is lost, while maintaining the majority of inter-sugar/base connections.

\section{Alternate/Future Directions}

\subsection{Phosphoramidites}

We have begun to explore the synthesis of nucleotide phosphoramidites using our selectively labeled nucleotides [8, 10, 104]. With this technology, RNAs up to 60 nucleotides can be synthesized. The power lies in the ability to not only place siteselective labels in a growing chain, but to place them at any desired position. A singlenucleotide isotopic enrichment strategy for unambiguous resonance assignment in nucleic acids through phosphoramidite chemistry was first purposed by Phan and Patel in order to assign small DNA tetrads [105]. Currently we are developing methodologies to streamline the production of these phosphoramidites and future work will explore their use in studying a number of RNA systems.

\subsection{Extension to PLOR}

Recently, a technique was published for the position-selective incorporation of nucleotide triphosphates into a growing RNA chain [106]. Its application is also reviewed in this issue of Methods. This technique offers much promise, and one can envision situations, especially for large RNAs, where one helix could be produced at a time with our alternating labeling patterns. A hypothetical example is illustrated below (Figure 6). The predicted secondary structure of a large non-coding RNA has been recently published [107]. Interestingly its architecture seems modular in nature, and one 
of the putative domains comprising its multi-domain structure is highlighted (Figure 6). This RNA is comprised of over 150 nt and 7 discreet helical regions. Assigning a fullylabelled sample of this RNA would be near impossible. However, by combining the power of our new alternating labeling and NOESY walk with the PLOR technique, each of the 7 helices could be independently labeled and assigned. In this way, facile assignment would be achieved without suffering from problems associated with crowding.

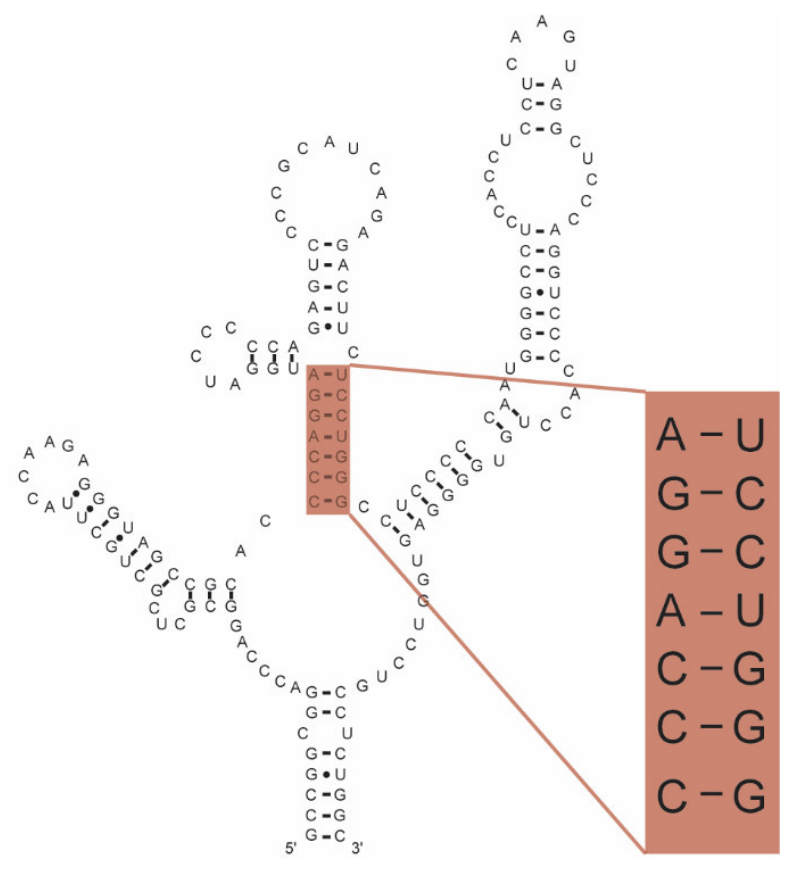

\subsection{Segmental Labeling}

Additionally, this alternating labeling pattern could be adopted in currently developed segmental labeling strategies. Current ligation strategies in both RNA and DNA are becoming more routine $[17,25-30,42]$. By synthesizing an RNA in multiple fragments and then using ligation methods a large reduction in spectral crowding can be achieved. By pairing this reduction with the above technologies, spectra of large RNAs should become greatly simplified. In the case of the SAM-II riboswitch, judicious design of 
fragments allowed for a crucial cytosine to contain the only labeled isotopes in the RNA, leading to unambiguous assignment of this residue and insightful exchange measurements [17].

\subsection{Placement of Deuteration}

Selective incorporation of deuteration on the sugar moieties will improve even further our proposed labeling strategy. Similar approaches were adopted in the past and their benefits were pronounced [37, 64]. By selectively deuterating positions H3', H4', H5', and $\mathrm{H} 5$ ", we postulate that the spectra will become better resolved with sharper lines due to improved relaxation properties of the remaining protons. This may also make possible the use of filtered/edited experiments to get the orthogonal data on the unlabeled sites of the ribose. In this way only one alternating label sample need be made, as both sets of information would be contained in it.

\section{Figure Captions}

Figure 1. General workflow for the assignment of RNA with a site-specific, isotopic, alternating labeled sample. First nucleotides are produced as described herein and elsewhere [3, 4, 9]. This is followed by a judicious choice of what labeling pattern to use. RNA is then synthesized and purified. Next, filtered, edited, and selected NOESY experiments are run and analyzed.

Figure 2. By using our selective labeling pattern the spectral complexity in a typical NOESY spectrum is greatly reduced. Without the ability to specifically edit protons that are attached to ${ }^{12} \mathrm{C}$ carbon nuclei the spectrum includes all intra-nucleotide sugar correlations to the base protons (Black). By using our alternating pattern and edited/edited experiments only correlations arising from protons directly attached to ${ }^{13} \mathrm{C}$ nuclei are seen (Cyan). This reduces spectral crowding and alleviates problems in the assignment process.

Figure 3. Available labeling patterns need for alternating patterns. ${ }^{13} \mathrm{C}$ labeled $\mathrm{C} 8 / \mathrm{C} 6$ base is enzymatically coupled to either ${ }^{13} \mathrm{C} \mathrm{C}^{\prime}$ ' or $\mathrm{C} 2$ ' labeled ribose. The $\mathrm{C} 5$ of uracil or cytosine is attached to a deuterium atom to both remove strong intra-nucleotide base correlations and improve relaxation properties of the $\mathrm{H} 6$ position. These labeled base and ribose moieties are 
chemo-enzymatically synthesized into NTPs and purified for use in T7 RNA polymerase based RNA transcription reactions.

Figure 4. Diagram illustrating the 5' to 3' NOESY walk through the backbone of an A-form RNA helix. In this example, the labeling patterns are, 1 ', $8-{ }^{13} \mathrm{C}$ ATP, 1 ', $6-{ }^{13} \mathrm{C}-5-{ }^{2} \mathrm{H}$ UTP, 2 ', $8-{ }^{13} \mathrm{C}$ GTP, and 2 ,, $6-{ }^{13} \mathrm{C}-5-{ }^{2} \mathrm{H}$ CTP. Starting at the 5 ' end, the $\mathrm{H} 1$ ' of Ade is correlated with its own $\mathrm{H} 8$ and the $\mathrm{H} 6$ of the adjacent Cyt. In turn this Cyt's H2' talks to its own $\mathrm{H} 6$ proton and that of the next base. In this way the walk is successfully correlated through the whole chain. $\left({ }^{13} \mathrm{C}\right.$-Cyan Squares)

Figure 5. Representative NOESY walk for a stretch of alternately $\left(1^{\prime}, 8-{ }^{13} \mathrm{C}\right.$ ATP $, 1^{\prime}, 6-{ }^{13} \mathrm{C}-5-{ }^{2} \mathrm{H}$ UTP, 2 ', $8-{ }^{13} \mathrm{C}$ GTP, and 2 ', $6-{ }^{13} \mathrm{C}-5-{ }^{2} \mathrm{H}$ CTP) labeled A-Site RNA (27 nt). Starting at the H1' of nucleotide $\mathrm{G} 1$, the NOESY walk was followed to the $\mathrm{H} 6$ of $\mathrm{C} 6$. Similar walks are achievable for the other helical tracts of A-Site. (A) Traced NOESY walk for nucleotides 1-6. (B) Representation of the correlations traced in (A). PDB: 1A3M [103].

Figure 6. Example where position-selective incorporation of nucleotide triphosphates (PLOR) could be successfully paired with our alternating labeling pattern [106]. A domain from a long non-coding RNA that is over 100 nucleotides long is used as a hypothetical example [107]. By labeling each of the 7 helices independently with our selective labels, rapid assignment of the helical regions can be achieved.

Acknowledgement:

This work was supported in part by the National Institute of General Medical Sciences (P50GM103297 to T.K.D.), and the National Science Foundation (DBI1040158 and CHE1213668 to T.K.D.).

\section{References}

[1] T.R. Cech, J.A. Steitz, Cell, 157 (2014) 77-94.

[2] H.M. Berman, J. Westbrook, Z. Feng, G. Gilliland, T.N. Bhat, H. Weissig, I.N. Shindyalov, P.E. Bourne, Nucleic Acids Res., 28 (2000) 235-242.

[3] A. P. Longhini, R.M. Leblanc, O. Becette, C. Salguero, C. H. Wunderlich, V. M. D'Souza, C. Kreutz,, T.K. Dayie, Nucleic Acid Res., (2015) doi:10.1093/nar/gkv1333.

[4] L.J. Alvarado, A.P. Longhini, R.M. LeBlanc, B. Chen, C. Kreutz, T.K. Dayie, in: H.B.-A. Donald (Ed.) Methods Enzymol., (2014), 133-162.

[5] T. Carlomagno, J. Magn. Res., 241 (2014) 126-136.

[6] B. Zhao, Q. Zhang, Current Opinion in Structural Biology, 30 (2015) 134-146.

[7] B. Fuertig, S. Nozinovic, A. Reining, H. Schwalbe, Curr. Opin. Struct. Biol., 30 (2015) 112-124.

[8] C.H. Wunderlich, M.A. Juen, R.M. LeBlanc, A.P. Longhini, T.K. Dayie, C. Kreutz, in: K. Zvi (Ed.) Methods Enzymol., (2015), 461-494.

[9] L.J. Alvarado, R.M. LeBlanc, A.P. Longhini, S.C. Keane, N. Jain, Z.F. Yildiz, B.S. Tolbert, V.M. D'Souza, M.F. Summers, C. Kreutz, T.K. Dayie, ChemBioChem, 15 (2014) 1573-1577.

[10] C.H. Wunderlich, R. Spitzer, T. Santner, K. Fauster, M. Tollinger, C. Kreutz, J. Am. Chem. Soc., 134 (2012) 7558-7569.

[11] L. Salmon, G.M. Giambasu, E.N. Nikolova, K. Petzold, A. Bhattacharya, D.A. Case, H.M. Al-Hashimi, J. Am. Chem. Soc., 137 (2015) 12954-12965.

[12] S. Yang, H.M. Al-Hashimi, J. Phys. Chem. B, 119 (2015) 9614-9626.

[13] L.E. Kay, J. Mol. Bio., 428 (2016) 323-331.

[14] J.-H. Ardenkjaer-Larsen, G.S. Boebinger, A. Comment, S. Duckett, A.S. Edison, F. Engelke, C. Griesinger, R.G. Griffin, C. Hilty, H. Maeda, G. Parigi, T. Prisner, E. Ravera, J. van Bentum, S. Vega, A. Webb, C. Luchinat, H. Schwalbe, L. Frydman, Angew. Chem. Int. Ed., 54 (2015) 9162-9185. 
[15] B. Fürtig, R. Schnieders, C. Richter, H. Zetzsche, S. Keyhani, C. Helmling, H. Kovacs, H. Schwalbe, J. Biomol. NMR, (2016) 1-15.

[16] B. Zhao, Q. Zhang, J. Am. Chem. Soc., 137 (2015) 13480-13483.

[17] B. Chen, R. LeBlanc, T. K. Dayie, Angew. Chem. Int. Ed., 55, (2016) 2724-2727.

[18] E. Kupce, G. Wagner, J. Magn. Res. Ser. B, 110 (1996) 309-312.

[19] B. Brutscher, J. Boisbouvier, E. Kupce, C. Tisne, F. Dardel, D. Marion, J.P. Simorre, J. Biomol. NMR, 19 (2001) 141-151.

[20] J. Cromsigt, B. van Buuren, J. Schleucher, S. Wijmenga, Methods Enzmol., 338 (2001) 371-399.

[21] G. Varani, F. Aboulela, F.H.T. Allain, Prog. Nucl. Magn. Reson. Spectrosc., 29 (1996), 51-127.

[22] S.S. Wijmenga, B.N.M. van Buuren, Prog. Nucl. Magn. Reson. Spectrosc., 32 (1998) 287-387.

[23] B. Furtig, C. Richter, J. Wohnert, H. Schwalbe, Chembiochem, 4 (2003) 936-962.

[24] L.G. Scott, M. Hennig, Methods Mol. Biol., 452 (2008) 29-36.

[25] P.J. Lukavsky, I. Kim, G.A. Otto, J.D. Puglisi, Nat. Struct. Biol., 10 (2003) 1033-1038.

[26] O. Duss, P.J. Lukavsky, F.H.T. Allain, Adv. Exp. Med. Biol., 992 (2012) 121-144.

[27] F.H.T. Nelissen, A.J. van Gammeren, M. Tessari, F.C. Girard, H.A. Heus, S.S. Wijmenga, Nucleic Acids Res., 36 (2008) e89.

[28] I. Kawahara, K. Haruta, Y. Ashihara, D. Yamanaka, M. Kuriyama, N. Toki, Y. Kondo, K. Teruya, J. Ishikawa, H. Furuta, Y. Ikawa, C. Kojima, Y. Tanaka, Nucleic Acids Res., 40 (2012).

[29] M.R. Stark, S.D. Rader, Methods Mol. Biol., 1126 (2014) 137-149.

[30] K. Lang, R. Micura, Nat. Protoc., 3 (2008) 1457-1466.

[31] D.P. Zimmer, D.M. Crothers, Proc. Natl. Acad. Sci. U.S.A., 92 (1995) 3091-3095.

[32] X. Chen, S.V.S. Mariappan, J.J. Kelley, III, J.H. Bushweller, E.M. Bradbury, G. Gupta, FEBS Lett., 436 (1998) 327-376.

[33] J.M. Louis, R.G. Martin, G.M. Clore, A.M. Gronenborn, J. Biol. Chem., 273 (1998) 2374-2378.

[34] J.L. Yan, J.H. Bushweller, Biochem. Biophys. Res. Commun., 284 (2001) 295-300.

[35] D.E. Smith, J.Y. Su, F.M. Jucker, J. Biomol. NMR, 10 (1997) 245-253.

[36] J.E. Masse, P. Bortmann, T. Dieckmann, J. Feigon, Nucleic Acids Res., 26 (1998) 2618-2624.

[37] G. Mer, W.J. Chazin, J. Am. Chem. Soc., 120 (1998) 607-608.

[38] D. MacDonald, P.Z. Lu, J. Am. Chem. Soc., 124 (2002) 9722-9723.

[39] M.H. Werner, V. Gupta, L.J. Lambert, T. Nagata, Methods Enzymol., 338 (2001) 283-304.

[40] C. Kojima, A. Ono, M. Kainosho, Methods in Enzymol., 338 (2001) 261-283.

[41] E.N. Nikolova, H.M. Al-Hashimi, J. Biomol. NMR, 45 (2009) 9-16.

[42] F.H.T. Nelissen, F.C. Girard, M. Tessari, H.A. Heus, S.S. Wijmenga, Nucleic Acids Res., 37 (2009) e114.

[43] F.H.T. Nelissen, E.P.M. Goossens, M. Tessari, H.A. Heus, Anal. Biochem., 475 (2015) 68-73.

[44] G.M. Clore, A.M. Gronenborn, Trends Biotech., 16 (1998) 22-34.

[45] J.P. Marino, H. Schwalbe, C. Anklin, W. Bermel, D.M. Crothers, C. Griesinger, J. Am. Chem. Soc., 116 (1994) 6472-6473.

[46] J.P. Marino, H. Schwalbe, C. Anklin, W. Bermel, D.M. Crothers, C. Griesinger, J. Biomol. NMR, 5 (1995) 87-92.

[47] C. Richter, H. Kovacs, J. Buck, A. Wacker, B. Furtig, W. Bermel, H. Schwalbe, J. Biomol. NMR, 47 (2010) 259-269.

[48] S. Saxena, J. Stanek, M. Cevec, J. Plavec, W. Kozminski, J. Biomol. NMR, 60 (2014) 91-98.

[49] H.A. Heus, S.S. Wijmenga, F.J.M. Vandeven, C.W. Hilbers, J. Am. Chem. Soc., 116 (1994) 49834984.

[50] S.S. Wijmenga, H.A. Heus, H.A.E. Leeuw, H. Hoppe, M. Vandergraaf, C.W. Hilbers, J. Biomol. NMR, 5 (1995) 82-86.

[51] V. D'Souza, A. Dey, D. Habib, M.F. Summers, J. Mol. Biol., 337 (2004) 427-442.

[52] Y. Miyazaki, R.N. Irobalieva, B.S. Tolbert, A. Smalls-Mantey, K. lyalla, K. Loeliger, V. D'Souza, H. Khant, M.F. Schmid, E.L. Garcia, A. Telesnitsky, W. Chiu, M.F. Summers, J. Mol. Biol., 404 (2010) 751772.

[53] J.E. Burke, D.G. Sashital, X. Zuo, Y.-X. Wang, S.E. Butcher, RNA, 18 (2012) 673-683.

[54] S.B. Miller, F.Z. Yildiz, J.A. Lo, B. Wang, V.M. D'Souza, Nature, 515 (2014) 591-+.

[55] E. Bonneau, N. Girard, S. Lemieux, P. Legault, RNA, 21 (2015) 1621-1632.

[56] S.C. Keane, X. Heng, K. Lu, S. Kharytonchyk, V. Ramakrishnan, G. Carter, S. Barton, A. Hosic, A. Florwick, J. Santos, N.C. Bolden, S. McCowin, D.A. Case, B.A. Johnson, M. Salemi, A. Telesnitsky, M.F. 
Summers, Science, 348 (2015) 917-921.

[57] R.D. Peterson, C.A. Theimer, H.H. Wu, J. Feigon J. Biomol. NMR, 28 (2004) 59-67.

[58] A. Grishaev, J. Ying, M.D. Canny, A. Pardi, A. Bax, J. Biomol. NMR, 42 (2008) 99-109.

[59] X. Zuo, J. Wang, P. Yu, D. Eyler, H. Xu, M.R. Starich, D.M. Tiede, A.E. Simon, W. Kasprzak, C.D.

Schwieters, B.A. Shapiro, Y.-X. Wang, Proc. Nat. Acad. Sci. USA, 107 (2010) 1385-1390.

[60] J. SantaLucia, L.X. Shen, Z. Cai, H. Lewis, I. Tinoco, Nucleic Acids Res., 23 (1995) 4913-4921.

[61] A.L. Breeze, Prog. Nuc. Magn. Reson. Spec., 36 (2000) 323-372.

[62] E.P. Nikonowicz, A. Sirr, P. Legault, F.M. Jucker, L.M. Baer, A. Pardi, Nucleic Acids Res., 20 (1992) 4507-4513.

[63] R.T. Batey, M. Inada, E. Kujawinski, J.D. Puglisi, J.R. Williamson, Nucleic Acids Res., 20 (1992) 4515-4523.

[64] M.J. Michnicka, J.W. Harper, G.C. King, Biochem., 32 (1993) 395-400.

[65] S. Quant, R.W. Wechselberger, M.A. Wolter, K.H. Worner, P. Schell, J.W. Engels, C. Griesinger, H.

Schwalbe, Tetrahedron Lett., 35 (1994) 6649-6652.

[66] J.V. Hines, S.M. Landry, G. Varani, I. Tinoco, J. Am. Chem. Soc., 116 (1994) 5823-5831.

[67] T.J. Tolbert, J.R. Williamson, J. Am. Chem. Soc., 118 (1996) 7929-7940.

[68] T.J. Tolbert, J.R. Williamson, J. Am. Chem. Soc., 119 (1997) 12100-12108.

[69] E.P. Nikonowicz, M. Michnicka, K. Kalurachchi, E. Dejong, Nucleic Acids Res., 25 (1997) 1390-1396.

[70] M.P. Latham, D.J. Brown, S.A. McCallum, A. Pardi, Chembiochem, 6 (2005) 1492-1505.

[71] K.T. Dayie, T.J. Tolbert, J.R. Williamson, J. Magn. Reson., 130 (1998) 97-101.

[72] E.P. Nikonowicz, Methods Enzymol., 338 (2001) 320-341.

[73] L.G. Scott, T.J. Tolbert, J.R. Williamson, Methods Enzymol., 317 (2000)18-38.

[74] J.H. Davis, M. Tonelli, L.G. Scott, L. Jaeger, J.R. Williamson, S.E. Butcher, J. Mol. Biol., 351 (2005)

371-382.

[75] P. Vallurupalli, L. Scott, M. Hennig, J.R. Williamson, L.E. Kay, J. Am. Chem. Soc., 128 (2006) 9346-

9347.

[76] J.A. Cromsigt, J. Schleucher, K. Kidd-Ljunggren, S.S. Wijmenga, J. Biomol. Struct. Dynam., 17 (2000) 211-219.

[77] J. Cromsigt, J. Schleucher, T. Gustafsson, J. Kihlberg, S. Wijmenga, Nucleic Acids Res., 30 (2002) 1639-1645.

[78] R.T. Batey, J.L. Battiste, J.R. Williamson, Methods Enzymol., 261 (1995) 300-322.

[79] A. Pardi, Methods Enzymol., 261 (1995) 350-380.

[80] J.E. Johnson, Jr., K.R. Julien, C.G. Hoogstraten, J. Biomol. NMR, 35 (2006) 261-274.

[81] T.K. Dayie, C. Thakur, J. Biomol. NMR, 47 (2010) 19-31.

[82] C. Thakur, J. Sama, M. Jackson, B. Chen, T.K. Dayie, J. Biomol. NMR, 48 (2010) 179-192.

[83] C. Thakur, Y. Luo, B. Chen, N. Eldho, T. Dayie, J. Biomol. NMR, 52 (2012) 103-114.

[84] E. Chiarparin, P. Pelupessy, G. Bodenhausen, Mol. Phys., 95 (1998) 759-767.

[85] P. Pelupessy, E. Chiarparin, G. Bodenhausen, J. Magn. Reson., 138 (1999) 178-181.

[88] P. Pelupessy, E. Chiarparin, Conc. Magn. Reson., 12 (2000) 103-124.

[89] F. Ferrage, T.R. Eykyn, G. Bodenhausen, Chemphyschem, 5 (2004) 76-84.

[90] A.L. Hansen, E.N. Nikolova, A. Casiano-Negroni, H.M. Al-Hashimi, J. Am. Chem. Soc., 131 (2009) 3818-3819.

[91] F. Massi, E. Johnson, C.Y. Wang, M. Rance, A.G. Palmer, J. Am. Chem. Soc., 126 (2004) 2247-

2256.

[92] D.M. Korzhnev, V.Y. Orekhov, L.E. Kay, J. Am. Chem. Soc., 127 (2005) 713-721.

[91] A. Dallmann, M. Sattler, Curr. Prot. Nucleic Acid Chem., 59 (2014) 7.22.21-27.22.19.

[92] A.L. Hansen, H.M. Al-Hashimi, J. Am. Chem. Soc., 129 (2007) 16072-16082.

[93] B. Zhao, A.L. Hansen, Q. Zhang, J. Am. Chem. Soc., 136 (2014) 20-23.

[94] C.P. Jaroniec, J. Boisbouvier, I. Tworowska, E.P. Nikonowicz, A. Bax, J. Biomol. NMR, 31 (2005)

231-241.

[95] P.K. Arthur, L.J. Alvarado, T.K. Dayie, Prot. Exp. Purif., 76 (2011) 229-237.

[96] R.M. Leblanc, A. P. Longhini, T.K. Dayie, Nucleic Acid Res., (in revision).

[97] J.F. Milligan, O.C. Uhlenbeck, in: J.N.A. James E. Dahlberg (Ed.) Methods Enzymol., (1989), 51-62.

[98] K.T. Dayie, J. Biomol. NMR, 32 (2005) 129-139.

[99] C. Helmling, S. Keyhani, F. Sochor, B. Fuertig, M. Hengesbach, H. Schwalbe, J. Biomol. NMR, 63

(2015) 67-76. 
[100] I. Kim, S.A. McKenna, E.V. Puglisi, J.D. Puglisi, RNA, 13 (2007) 289-294.

[101] L.E. Easton, Y. Shibata, P.J. Lukavsky, RNA, 16 (2010) 647-653.

[102] Y. Luo, N.V. Eldho, H.O. Sintim, T.K. Dayie, Nucleic Acids Res., 39 (2011).

[103] D. Fourmy, S. Yoshizawa, J.D. Puglisi, J. Mol. Biol., 277 (1998) 333-345.

[104] S. Neuner, T. Santner, C. Kreutz, R. Micura, Chemistry, 21 (2015) 11634-11643.

[105] A.T. Phan, D.J. Patel, J. Am. Chem. Soc., 124 (2002) 1160-1161.

[106] Y. Liu, E. Holmstrom, J. Zhang, P. Yu, J. Wang, M.A. Dyba, D. Chen, J. Ying, S. Lockett, D.J. Nesbitt, A.R. Ferre-D'Amare, R. Sousa, J.R. Stagno, Y.-X. Wang, Nature, 522 (2015) 368-376.

[107] I.V. Novikova, S.P. Hennelly, K.Y. Sanbonmatsu, Nucleic Acids Res., 40 (2012) 5034-5051. 


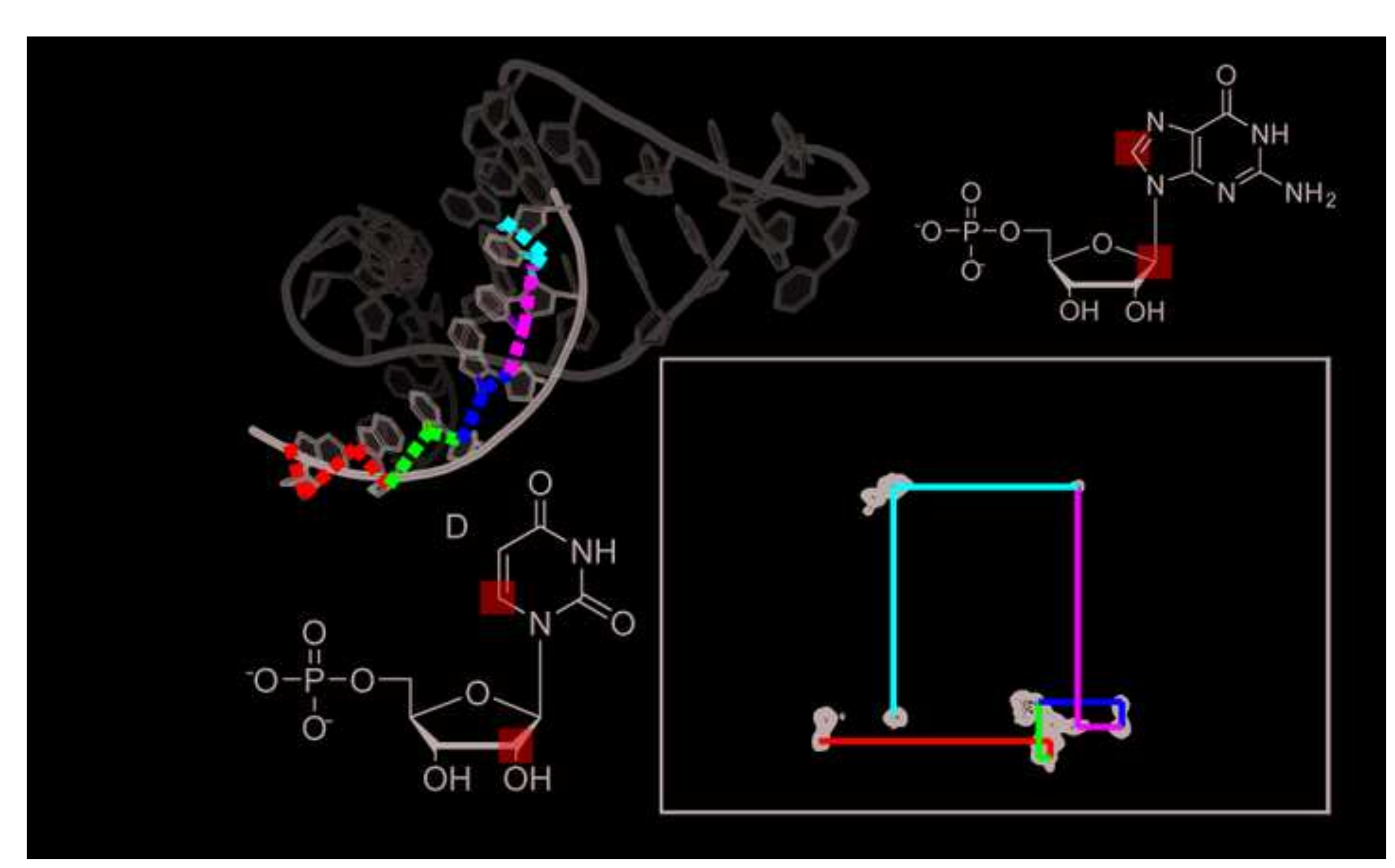

